\title{
Development, evaluation and validation of a new instrument for measurement quality of life in the parents of children with chronic disease
}

\author{
Małgorzata Farnik*, Grzegorz Brożek², Władysław Pierzchała', Jan E Zejda², Michał Skrzypek³ Łukasz Walczak $^{4}$
}

\begin{abstract}
Background: Childhood chronic disease may affect patients' and their family's functioning. Particularly parents, who play an important role in cooperation between patient and health care professionals, report impaired health related quality of life (HRQOL). The aim of this study was development, evaluation and validation of a new instrument: Quality of Life in a Child's Chronic Disease Questionnaire (QLCCDQ). The questionnaire is addressed to parents of children with a chronic disease.
\end{abstract}

Methods: Study design included semi structured interview and qualitative study, which allowed to identify most troublesome problems. Following the results the questionnaire was developed, which consists of 15 questions and covers domains - emotions, patients -perceived symptoms, roles limitations. An observational study involving parents of asthma and diabetes children was conducted to assess the psychometric characteristics of the measure. Psychometric testing was based on the reliability of defined subscales, construct validity, reproducibility assessment, as well as comparison between stable/unstable disease stages and parents of healthy children.

Results: Most troublesome concerns for parents of child with chronic disease included emotional distress and feeling depressed due to child's disease, avoiding social interactions due to child's disease or symptoms. 98 parents of children with asthma or insulin - depended diabetes participated in the psychometric testing of QLCCDQ. Internal consistency reliability for the defined subscales ranged between 0.77 and 0.93 . Reproducibility based on the weighted kappa coefficients showed expected level of agreement and was almost perfect in case of 8 questions, substantial for 5 questions and moderate for 2 questions. QLCCDQ demonstrated very good construct validity - all subscales showed statistically significant correlations ranging from 0.4 to 0.9 . QLCCDQ scores differed significantly by clinical status - parents of children qualified as stable presented higher scores in most subscales in comparison to parents of children with unstable disease.

Conclusions: The QLCCDQ shows good internal consistency, test-retest reliability, and construct validity. The questionnaire may be useful in helping to understand the impact of chronic child's disease on parental perception of health outcomes.

\section{Background}

An increasing interest of the impact of disease on everyday functioning is leading to the development and implementation of health - related quality of life (HRQOL) measures in many studies. Chronic disease may affect not only patients' functioning, but other family members as well. Childhood chronic disease involves all family

\footnotetext{
* Correspondence: mfarnik@interia.pl

'Department of Pneumonology, Medical University of Silesia, Katowice, Poland

Full list of author information is available at the end of the article
}

members, particularly parents, who play an important role in the cooperation between patients and health care professionals. Higher level of psychological distress in parents of children with chronic disease has been reported in several studies [1-5]. Parents experience limitations in regular daily activities and anxiety due to the child's disease [6]. Clinical experience shows that caregiver HRQOL and perception of child's symptoms are important in the diagnosis and control of established asthma [7]. The perspective of both the child and the parent is important in assessing treatment outcomes and

\section{Biomed Central}


planning support strategies. Pediatrics is unique among medical specialties especially because of the presence of parents when health care is provided for the child. This requires a family-oriented approach to care [8].

HRQOL assessment in childhood chronic disease could either be measured as parent-proxy measures of the child's quality of life or as self-reported parental quality of life. Several studies show that parents are reliable at reporting symptoms and physical function, but less reliable at reporting cognitive and emotional wellbeing of the child [9].

HRQOL of parents could be assessed by a wide range of general status questionnaires such as the Medical Outcomes Survey Short Form 36 (SF 36) [10], EuroQol [11], Health Utility Index [12], and the Quality of Well being Scale [13]. However, these measures do not to allow the assessment of the burden of the child's disease on the parent's HRQOL. Available general questionnaire proposed for caregivers - Pediatric Inventory for Parents $[14,15]$ covers different aspects of parental HRQOL, but no roles function, the questionnaire requires psychometric examination. Another questionnaire which could be used in wide range of clinical conditions is the Impact on Family Function Scale [16]. This measure focuses on impact of the child's disease on family and covers four domains: financial family/social, mastery, personal - strain.

Most of the existing validated measures are specific questionnaires, dedicated to parents of children with a particular disease and are not recommended as a measure of HRQOL assessment for other clinical conditions. HRQOL of parents of children with diabetes could be assessed by Well-being and Satisfaction of Caregiver's of Children with Diabetes Questionnaire (WE-CARE) [17], Parents Diabetes Quality of Life questionnaire (PDQOL) [5]. The WE-CARE questionnaire is validated measure which covers parents' psychosocial well-being, satisfaction with treatment, ease of insulin use, and treatment acceptance. The PDQOL assesses parental life satisfaction, impact of child's diabetes and disease related worries. Another example of disease specific measure is Paediatric Asthma Caregivers' Quality of Life Questionnaire (PACQLQ), covering three domains: symptoms, emotional function and activity limitation [18]. PACQLQ is 13 -items self-administered questionnaire, which was validated and includes emotional and physical context of impairment. Another example of a specific measure to assess parental HRQOL is the questionnaire developed for parents of children with recurrent ear, nose and throat infections [19], which includes domains of emotional health and daily disturbances (PAR-ENT-QoL).

The proposed questionnaire, the Quality of Life in the Child's Chronic Disease Questionnaire (QLCCDQ) deals with daily problems and limitations that concern parents of children with chronic disease. Compared to existing
HRQOL measures in parents - the newly developed parental HRQOL assessment and symptom proxy measure could be implemented in different clinical conditions and covers both impact of disease on family and psychosocial aspects of parental functioning. Parental HRQOL assessment would be helpful to optimize clinical judgment as well as to improve clinical decisions. Childhood diabetes and asthma are examples of chronic disease which require continuous monitoring and treatment and were chosen for questionnaire development and validation. The purpose of this paper is to describe the development of the QLCCDQ and report on the assessment of its validity and reliability.

\section{Methods}

The QLCCDQ is a self - report measure of the parent's HRQOL. Only the symptoms subscale is a proxy measure of the parent's HRQOL. The QLCCDQ consists of 15 questions and covers: emotions (4 questions); patientperceived symptoms (3 questions); and role limitations (8 questions) including social (3 questions), occupational (3 questions), and family roles (2 questions). The QLCCDQ is a self - administered questionnaire, based on a 7 point Likert scale from 1 (most bothered or limited) to 7 (not bothered or limited). The responses concern parental perceptions of the child and their condition over a previous two-week period. Examples of questions representing each domain of QLCCDQ have been demonstrated in Table 1. Some of items were adopted from the SF-36, which is used extensively in a wide range of medical conditions. The scale is based on 7-point scale, which was previously used in other validated measures as PACQLQ. As well as some questions (for example activity limitations) were similar to PAQLQ and mini Asthma Quality Of Life Questionnaire.

The questionnaire was devised based on the multistep procedure $[20,21]$ which is summarized in the study design. The first step was to identify needs and define the operational objectives [22,23]. The questionnaire was developed from an initial inventory of questions and a qualitative study. Cognitive debriefing interviews were conducted to assess respondents' comprehension of questions and response scales. Psychometric testing of QLCCDQ was performed with a group of parents of children with diabetes or asthma. The questionnaires were distributed in a hospital outpatient department, were self - completed by parents and returned to study physicians.

Participants of the study were chosen based on convenience samples. Approval from an ethics committee at the authors' university was obtained by the study center.

\section{Study design}

Questionnaire development was based on a multi-stage procedure which included the processes of item 
Table 1 QLCCDQ - examples of questions

\begin{tabular}{|c|c|c|c|c|c|c|c|}
\hline Domains & & & & & & & \\
\hline \multicolumn{8}{|l|}{ Symptoms } \\
\hline & \multicolumn{7}{|c|}{ Did the child show any worrying symptoms? } \\
\hline & All the time & Most of the time & Often & Sometime & Seldom & Very seldom & Never \\
\hline \multicolumn{8}{|l|}{ Emotions } \\
\hline & \multicolumn{7}{|c|}{ Have you experienced anxiety because of your child's health problems? } \\
\hline & All the time & Most of the time & Often & Sometimes & Seldom & Very seldom & Never \\
\hline \multicolumn{8}{|l|}{ Role functioning } \\
\hline & \multicolumn{7}{|c|}{$\begin{array}{l}\text { Please indicate how much you have been limited by your child's disease in listed activities in past two weeks - Social activities } \\
\text { (going to church, cinema, visiting friends) }\end{array}$} \\
\hline & Extremely limited & Very limited & Quite limited & Moderately limited & Somewhat limited & Hardly limited & Not limited \\
\hline \multicolumn{8}{|l|}{ Occupational } \\
\hline & \multicolumn{7}{|c|}{ Please indicate how much you have been limited by your child's disease in work related activities in past two weeks } \\
\hline & Extremely limited & Very limited & Quite limited & Moderately limited & Somewhat limited & Hardly limited & Not limited \\
\hline \multicolumn{8}{|l|}{ Family } \\
\hline & \multicolumn{7}{|c|}{ Do you struggle to find time to spend with other family members (spouse, another child) because of your child' disease? } \\
\hline & Extremely limited & Very limited & Quite limited & Moderately limited & Somewhat limited & Hardly limited & Not limited \\
\hline $\begin{array}{l}\text { Scaling for answers } \\
\text { (points) }\end{array}$ & 1 & 2 & 3 & 4 & 5 & 6 & 7 \\
\hline
\end{tabular}

identification, questionnaire development, and psychometric testing:

Process of item identification:

- Semi structured interview with health professionals and parents of children with chronic disease (diabetes, asthma, and eczema)

- identification of most the troublesome problems

- initial inventory development with a 5 point Likert scale rating the importance of each item

- qualitative study among parents of children with chronic disease

Process of questionnaire development:

- questionnaire development based on results of qualitative study

- cognitive debriefing (to assess the comprehension of the questionnaire)

- development of the final version of the questionnaire

- cognitive debriefing of the final version of the questionnaire

The last phase of the study was psychometric testing.

- The validation process included internal consistency, construct validity, reproducibility, and knowngroup analysis (children with asthma and diabetes)

\section{Description of process}

Semi structured interviews and a literature review were used to develop an initial inventory listing the most troublesome problems for parents of children with chronic disease. Health professionals (pediatricians, nurses) and parents of children with diabetes, asthma or eczema were invited for an interview to help develop this inventory. In the qualitative study which followed, parents were asked to choose from the inventory, which concerns were relevant to their situation and rate the importance of several troublesome issues (from 1 - not important/troublesome to 5 very important/troublesome). Not all parents rated all the items. Inclusion criteria for participation in this phase of the questionnaire development required the child to have a clinical diagnosis of asthma (with possible perennial rhinitis as concomitant disease) or eczema or diabetes; symptoms presence or the diagnose was established at least 12 months before the study; no other social and psychological problems which may have an impact on family functioning or ability to respond (such alcohol/drug abuse, psychiatric diseases), and; willingness to provide consent to participate.

In the next phase, cognitive debriefing interviews were conducted involving parents recruited from the qualitative study. Cognitive debriefing was done twice - first on the primary version and second on the revised questionnaire to ensure that respondents could understand and complete the questionnaire. 
The psychometric testing phase to validate the questionnaire consisted of measuring internal consistency, construct validity, reproducibility, and known - group analysis. Psychometric testing was conducted in outpatient departments involving parents of children with asthma or diabetes. Asthma children represented a wide range of severity: episodic, mild and moderate. Children with diabetes were insulin - dependent with or without complications. Both asthma and diabetes study groups included patients with and without satisfactory disease control. Subjects were excluded if there were significant co-morbidities in the child that could impact their quality of life and other social and psychological problems which could have an impact on family functioning or ability to respond. Once completed, the questionnaires were returned to study physicians.

Comparison of HRQOL results in parents whose child was assessed as stable and parents with uncontrolled asthma or diabetes were conducted for both groups. Asthma control is defined based on GINA guidelines as daytime symptoms present less than twice a week, rescue medication use less than twice a week, no nocturnal symptoms, no limitations in physical activity, normal or near normal lung function values in lung function test [24].

Diabetes control was based on glucose and hemoglobin A1c (Hb A1c) levels. Patients were classified as stable if $\mathrm{Hb} \mathrm{A} 1 \mathrm{c}$ below 6.5\% was achieved, as well as glucose if fasted and between meals ranged between 3.9 and $6.1 \mathrm{mmol} / \mathrm{l}$, after meals less than $8.9 \mathrm{mmol} / \mathrm{l}$ [25].

The control group for the psychometric testing consisted of a volunteer group of parents of healthy children. The final version of QLCCDQ was completed. As typical childhood diseases or even prophylaxis (vaccinations) could focus parental attention on health - related problems it was important to find out if all questions included in the questionnaire were clearly related to chronic disease conditions. For this reason, we included a control group.

\section{Statistical analysis}

The statistical analysis was performed using standard procedures available in the Statistica 7.1 package (StatSoft Inc, USA) and SAS, version 9.2 (SAS Institute Inc., Gary, NC). Normality of distributions of continuous variables was assessed by the Shapiro-Wilk test. Statistical significance of differences between continuous variables was analyzed by the Student's t-test and Analysis of Variance. If a non-normal distribution was found, the MannWhitney U test and Kruskal-Wallis tests were used, respectively. Differences between categorical variables were examined by the Chi-square test. Correlations between variables with non-normal distributions were measured by Spearman's rank correlation coefficient. The reliability of the defined subscales was measured by the Cronbach's alpha. The statistical inferences were based on the level of significance of $\mathrm{p}<0.05$.

\section{Results}

Semi structured interviews were conducted on the group of health professionals (18 pediatricians, 10 nurses) and 22 parents of children with diabetes, asthma or eczema. Health care professionals raised the emotional context of disease, distress and anxiety, potential limitation of occupational roles as troublesome areas for parents. Parents identified emotional distress, time limited for other family members and professional career, and decreased social interactions as troublesome areas. All important issues raised by respondents were incorporated into the initial inventory, which was distributed during qualitative study.

\section{Qualitative study}

The qualitative study was conducted among 65 parents of children aged 6-14 years old, mean age 9.23 (SD 2.06), with chronic disease including asthma, eczema or diabetes [Table 2].

Based on the qualitative study, the most troublesome issues related to the child's disease as identified by parents were emotional distress and feeling depressed, avoiding social interactions, and time limited for other family members. Other concerns reported by parents reflected limitations in occupational activity/professional career and social activities.

Among those parents who rated the concern as relevant, the highest means were for experience anxiety due to child's chronic disease, worried or concerned about child's future, and limitations in social activities due to their disease [Table 3]. We did not find statistically significant differences in the responses between mothers and fathers.

\section{Cognitive debriefing}

Cognitive debriefing involved 10 parents of children with diabetes and 15 parents of children with asthma.

Table 2 Qualitative study - demographic data

\begin{tabular}{|c|c|c|c|c|}
\hline & $\begin{array}{c}\text { Diabetes } \\
\mathrm{n}=22\end{array}$ & $\begin{array}{c}\text { Asthma } \\
n=26\end{array}$ & $\begin{array}{l}\text { Asthma and rhinitis } \\
\qquad n=3\end{array}$ & $\begin{array}{l}\text { Eczema } \\
\mathrm{n}=14\end{array}$ \\
\hline \multicolumn{5}{|l|}{ Parent's gender } \\
\hline Male & 8 & 7 & 1 & 4 \\
\hline Female & 14 & 19 & 2 & 10 \\
\hline \multicolumn{5}{|l|}{ Child's gender } \\
\hline Male & 7 & 8 & 2 & 5 \\
\hline Female & 15 & 18 & 1 & 9 \\
\hline \multicolumn{5}{|l|}{ Child's age } \\
\hline Mean (SD) & $9.4(2.1)$ & $8.8(1.9)$ & $8.0(2.0)$ & $9.8(2.3)$ \\
\hline Min-Max & $6-13$ & $6-14$ & $6-10$ & $6-13$ \\
\hline
\end{tabular}


Table 3 Reported importance of parent's concerns due to child's chronic disease

\begin{tabular}{|c|c|c|c|c|c|}
\hline Parents' reported concerns & $\begin{array}{l}\text { Percent of } \\
\text { respondents }\end{array}$ & $\begin{array}{c}\text { Mean } \\
\text { scores }\end{array}$ & SD & Min & Max \\
\hline Experience anxiety due to child's chronic disease & 100 & 4.9 & 0.2 & 4 & 5 \\
\hline Worried or concerned about child's future, due to their disease & 100 & 4.9 & 0.2 & 4 & 5 \\
\hline Giving up meeting friends because of child's disease & 100 & 4.7 & 0.5 & 4 & 5 \\
\hline Feeling depressed because of child's disease & 100 & 4.8 & 0.4 & 4 & 5 \\
\hline Experience anxiety due to child's disease/symptoms & 100 & 4.8 & 0.4 & 4 & 5 \\
\hline $\begin{array}{l}\text { Struggling to find time to spend with other family members (spouse, another child) because } \\
\text { of child's disease }\end{array}$ & 95.4 & 4.7 & 0.5 & 4 & 5 \\
\hline Limitation in attention given to other family members & 95.4 & 4.7 & 0.5 & 4 & 5 \\
\hline Feeling guilty due to child's disease & 7.7 & 4.6 & 1.1 & 3 & 5 \\
\hline Impact of diesase on own or family's financial situation & 27.7 & 3.5 & 1.1 & 2 & 5 \\
\hline Limitations in work related activities & 75.4 & 4.5 & 0.5 & 4 & 5 \\
\hline Refrained from hobbies/entertainment because of child's disease & 86.1 & 4.6 & 0.5 & 4 & 5 \\
\hline Limitations in household activities (housework, shopping, cleaning) & 87.7 & 4.7 & 0.5 & 4 & 5 \\
\hline Feeling shame as the result of child's disease & 3.1 & 5 & 0.0 & 5 & 5 \\
\hline
\end{tabular}

1) percentage of parents who rated the concern as relevant.

2) 5 -point scales used (1:not important to 5 :very important).

The debriefing resulted in three questions being removed and the wording of five questions being changed. After making the final version all questions were assessed as viable, relevant to parental concerns about their child's disease, and easy to understand.

\section{Psychometric testing}

Parents of 98 children aged 5-14 years old [mean age 9.07 (SD 2.08)] with asthma or diabetes [Table 4] completed the questionnaire. The control group consisted of 21 parents of healthy children. There were no significant differences in the child's age between the asthma, diabetes groups, and control groups.

\section{Internal consistency reliability}

The reliability of the defined subscales was evaluated by Cronbach's $\alpha$. All subscales that were supposed to represent a single - construct scale achieved Cronbach's alpha at least 0.7. The values for subscales ranged between 0.77 and 0.93 [Table 5] thus suggesting acceptable internal consistency of the questionnaire.

\section{Construct validity}

Statistically important positive correlations were observed between all QLCCDQ dimensions defined by questionnaire's subscales [Table 6]. Better (higher scores) of defined subscales correlated positively with other subscales as expected; the Spearman coefficients ranged from 0.4 to 0.9. As well, positive correlations were found between most questions representing each subscale [Table 7].

\section{Reproducibility}

Reproducibility of answers was examined in a subgroup of 22 parents of asthma patients. The questionnaire was distributed twice - parents were asked to complete the questionnaire again 2 hours after first completion. According to the values of weighted kappa coefficients

Table 4 Psychometric testing - demographic data

\begin{tabular}{|c|c|c|c|c|c|}
\hline & $\begin{array}{c}\text { Diabetes } \\
\mathrm{n}=31\end{array}$ & $\begin{array}{l}\text { Asthma } \\
\mathrm{n}=67\end{array}$ & $\begin{array}{l}\text { Stable patients } \\
n=73\end{array}$ & $\begin{array}{c}\text { Unstable patients } \\
n=25\end{array}$ & $\begin{array}{c}\text { Controls } \\
n=21\end{array}$ \\
\hline \multicolumn{6}{|l|}{ Parent's gender } \\
\hline Male & 13 & 22 & 19 & 8 & 9 \\
\hline Female & 18 & 45 & 54 & 17 & 12 \\
\hline \multicolumn{6}{|l|}{ Child's gender } \\
\hline Male & 16 & 40 & 62 & 13 & 11 \\
\hline Female & 15 & 27 & 11 & 12 & 10 \\
\hline \multicolumn{6}{|l|}{ Child's age } \\
\hline Mean (SD) & $9.2(2.7)$ & $8.5(1.3)$ & $8.6(1.6)$ & $9.3(2.5)$ & $9.0(1.9)$ \\
\hline Min-Max & $5-13$ & $7-12$ & $5-13$ & $5-14$ & $5-13$ \\
\hline
\end{tabular}


Table 5 QLCCDQ subscales reliability

\begin{tabular}{ll}
\hline Domain & Cronbach's $\boldsymbol{\alpha}$ \\
\hline Family roles & 0.77 \\
Social roles & 0.79 \\
Occupational roles & 0.91 \\
Roles limitations & 0.91 \\
Symptoms & 0.93 \\
Emotions & 0.91 \\
\hline
\end{tabular}

the level of agreement was almost perfect in case of 8 questions (0.81-1.00), substantial for 5 questions (0.61$0.80)$ and moderate for 2 questions $(0.41-0.60)$ [Table 8 ].

\section{Known-groups analysis}

The discriminative validity was determined by comparing mean scores between parents of children with conditions and parents of control children as well as between parents of children with stable conditions and those with unstable conditions. Higher HRQOL scores were found in parents of control children than parents of children with a chronic condition [Table 9]. Emotions and symptoms domains were most impaired in the chronic disease group. The analysis also revealed that QLCCDQ scores were significantly higher in the group of parents of stable children in comparison with unstable children. Only one subscale didn't show any significant differences - occupational roles functioning [Table 9].

At this stage, the analysis revealed, that QLCCDQ results showed that mother's scores were lower in comparison with father's scores in most subscales [Table $10]$.

\section{Discussion}

As chronic child's disease may have an impact on the entire family functioning - parents of children representing common chronic diseases in childhood were invited
Table 7 Spearman's correlations between questions representing subscales

\begin{tabular}{|c|c|c|c|}
\hline \multirow{2}{*}{$\begin{array}{l}\text { QLCCDQ } \\
\text { subscale }\end{array}$} & \multicolumn{3}{|c|}{ Question } \\
\hline & & 6 & 13 \\
\hline \multirow[t]{2}{*}{ Family roles } & 6 & - & \\
\hline & 13 & $\begin{array}{c}0.62546 \\
(<.0001)\end{array}$ & - \\
\hline
\end{tabular}

Social roles

\begin{tabular}{cccc} 
& 1 & 2 & 14 \\
\hline 1 & - & & \\
\hline 2 & 0.79839 & - & \\
& $(<.0001)$ & & \\
\hline 14 & $\mathbf{0 . 6 2 1 3 9}$ & $\mathbf{0 . 7 2 0 4 2}$ & - \\
& $(<.0001)$ & $(<.0001)$ &
\end{tabular}

\begin{tabular}{|c|c|c|c|c|}
\hline & & 10 & 12 & 15 \\
\hline \multirow[t]{3}{*}{ Occupational Roles } & 10 & - & & \\
\hline & 12 & $\begin{array}{l}0.38899 \\
(0.0040)\end{array}$ & - & \\
\hline & 15 & $\begin{array}{c}0.63701 \\
(<.0001)\end{array}$ & $\begin{array}{l}0.26247 \\
(0.0576)\end{array}$ & - \\
\hline
\end{tabular}

\begin{tabular}{|c|c|c|c|c|}
\hline \multirow{4}{*}{ Symptoms perception } & & 4 & 5 & 8 \\
\hline & 4 & - & & \\
\hline & 5 & $\begin{array}{c}0.67511 \\
(<.0001)\end{array}$ & - & \\
\hline & 8 & $\begin{array}{c}0.68810 \\
(<.0001)\end{array}$ & $\begin{array}{c}0.66283 \\
(<.0001)\end{array}$ & - \\
\hline
\end{tabular}

Emotions

\begin{tabular}{ccccc} 
& 3 & 7 & 9 & 11 \\
\hline 3 & - & & & \\
\hline 7 & $\mathbf{0 . 3 5 2 7 1}$ & - & & \\
& $(0.0096)$ & & & \\
\hline 9 & $\mathbf{0 . 3 3 6 4 9}$ & $\mathbf{0 . 5 8 5 3 9}$ & - & \\
& $(\mathbf{0 . 0 1 3 8 )}$ & $(<.0001)$ & & \\
\hline 11 & $\mathbf{0 . 3 0 3 3 0}$ & $\mathbf{0 . 4 3 8 3 3}$ & $\mathbf{0 . 4 7 3 4 9}$ & - \\
& $\mathbf{( 0 . 0 2 7 3 )}$ & $\mathbf{( 0 . 0 0 1 0 )}$ & $\mathbf{( 0 . 0 0 0 3 )}$ & \\
& & & &
\end{tabular}

p-value $<0.05$ in brackets (significant in bold).

Table 6 QLCCDQ subscales Spearmans' correlations

\begin{tabular}{|c|c|c|c|c|c|c|}
\hline & Family roles & Social roles & Occupational roles & Roles limitations & Symptoms perception & Emotions \\
\hline \multicolumn{7}{|l|}{$\begin{array}{l}\text { Domain } \\
\text { QLCCDQ }\end{array}$} \\
\hline Family roles & - & & & & & \\
\hline Social roles & $\begin{array}{l}0.7 \\
(0.0000001)\end{array}$ & - & & & & \\
\hline $\begin{array}{l}\text { Occupational } \\
\text { Roles }\end{array}$ & $\begin{array}{l}0.7 \\
(0.0000001)\end{array}$ & $\begin{array}{l}0.7 \\
(0.0000001)\end{array}$ & - & & & \\
\hline Roles limitations & $\begin{array}{l}0.8 \\
(0.0000001)\end{array}$ & $\begin{array}{l}0.9 \\
(0.0000001)\end{array}$ & $\begin{array}{l}0.9 \\
(0.0000001)\end{array}$ & - & & \\
\hline Symptoms perception & $\begin{array}{l}0.5 \\
(0.00003)\end{array}$ & $\begin{array}{l}0.4 \\
(0.002)\end{array}$ & $\begin{array}{l}0.4 \\
(0.0007)\end{array}$ & $\begin{array}{l}0.5 \\
(0.00003)\end{array}$ & - & \\
\hline Emotions & $\begin{array}{l}0.7 \\
(0.0000001)\end{array}$ & $\begin{array}{l}0.6 \\
(0.0000001)\end{array}$ & $\begin{array}{l}0.6 \\
(0.00001)\end{array}$ & $\begin{array}{l}0.7 \\
(0.0000001)\end{array}$ & $\begin{array}{l}0.9 \\
(0.0000001)\end{array}$ & - \\
\hline
\end{tabular}

p-value $<0.05$ in brackets (significant in bold). 
Table 8 Weighted kappa for QLCCDQ questions

\begin{tabular}{ccc}
\hline $\begin{array}{c}\text { Question } \\
\text { nr }\end{array}$ & Weighted kappa & $\mathbf{9 5 \%} \mathbf{C l}$ \\
\hline 1 & 0.6 & $0.2 ; 0.9$ \\
2 & 0.8 & $0.6 ; 0.9$ \\
3 & 0.9 & $0.8 ; 1.0$ \\
4 & 0.9 & $0.8 ; 1.0$ \\
5 & 0.9 & $0.8 ; 1.0$ \\
6 & 0.8 & $0.7 ; 1.0$ \\
7 & 1.0 & $1.0 ; 1.0$ \\
8 & 0.9 & $0.9 ; 1.0$ \\
9 & 0.6 & $0.3 ; 1.0$ \\
10 & 0.9 & $0.8 ; 1.0$ \\
11 & 0.6 & $0.2 ; 1.0$ \\
12 & 0.8 & $0.6 ; 1.0$ \\
13 & 0.6 & $0.2 ; 1.0$ \\
14 & 0.8 & $0.3 ; 1.0$ \\
15 & 0.8 & $0.6 ; 1.0$ \\
\hline
\end{tabular}

$\mathrm{p}<0.01$.

to participate in a qualitative study to identify their most troublesome concerns. Most parents identified emotional concerns and impact on roles functioning as primary concerns. Parents complained about their limitation in attention and time offered to other family members, limitation in work related activities, as well as daily house-hold activities. Based on the qualitative study, the questionnaire was developed and cognitive debriefing was subsequently used to generate the final version of the new tool.

This study investigated the validity of newly developed questionnaire addressing the HRQOL of parents of children with a chronic condition. Psychometric analyses based on a sample of 65 parents of children with asthma or diabetes was used to evaluate the validity of the questionnaire. With the satisfactory results of the QLCCDQ found in this study, our results would suggest that this questionnaire could be used in clinical practice. Psychometric properties for the questionnaire including internal consistency, construct validity and reproducibility were satisfactory. Internal consistency of QLCCDQ scores achieved acceptable levels of Cronbach' alpha.
The QLCCDQ demonstrated good reproducibility with kappa coefficients of at least substantial for most questions.

Construct validity of the questionnaire demonstrated positive correlations between all defined subscales. Parents of children with chronic disease demonstrated lower HRQOL mean scores in all subscales in comparison to parents of control children. The comparison between QLCCDQ scores of parents of stable children and unstable children has shown that clinical status had an impact on parental functioning. Significantly lower QLCCDQ scores have been observed for most subscales for parents of children with unstable conditions. The only exception was the occupational roles subscale where no differences were found between parents of stable and unstable children.

The initial inventory didn't show that parental concerns due to a child' disease differed between mothers and fathers. Thus HRQOL questionnaire should not include different items for mothers and fathers. As it was found in other studies our analysis of QLCCDQ results showed that the HRQOL due to child's disease was more impaired in mothers [26].

Our study showed that the QLCCDQ could bring new insights into health related outcomes in childhood diseases. The questionnaire showed that HRQOL scores in parents were statistically lower in the case of chronic disease in comparison with parents of healthy children for all subscales. It is worthwhile noting that answers to only one question, feeling guilty due to the child's disease, didn't showed any differences between the control and the chronic condition group in the psychometric testing. Despite of qualitative study results showing that guilty feeling as the result of child's disease were found as an important concern, no differences were found between scores of controls and chronic conditions. This may be important when using the QLCCDQ in other childhood chronic diseases as the child's disease may have an impact on contexts such as emotional functioning.

Parental HRQOL assessment using QLCCDQ could be beneficial in clinical practice. The implementation of

Table 9 QLCCDQ scores

\begin{tabular}{|c|c|c|c|c|c|c|c|c|c|c|}
\hline \multirow[t]{2}{*}{ Domain } & \multicolumn{2}{|c|}{ Stable } & \multicolumn{2}{|c|}{ Unstable } & \multirow[t]{2}{*}{ p-value } & \multicolumn{2}{|c|}{ Chronic disease } & \multicolumn{2}{|c|}{ Controls } & \multirow[t]{2}{*}{ p-value } \\
\hline & Mean & SD & Mean & SD & & Mean & SD & Mean & SD & \\
\hline Family roles & 5.6 & 1.2 & 4.6 & 1.4 & 0.03 & 5.2 & 1.3 & 6.3 & 0.9 & 0.0004 \\
\hline Social roles & 5.8 & 1.0 & 4.9 & 1.6 & 0.01 & 5.5 & 0.6 & 6.6 & 1.3 & 0.00002 \\
\hline Occupational & 5.4 & 1.4 & 4.7 & 1.8 & $>0.5$ & 5.1 & 0.8 & 6.4 & 1.7 & 0.0001 \\
\hline Roles limitations & 5.5 & 1.1 & 4.7 & 1.5 & 0.04 & 5.3 & 0.7 & 6.5 & 1.4 & 0.00002 \\
\hline Emotions & 4.5 & 1.1 & 3.8 & 1.1 & 0.001 & 4.3 & 1.0 & 6.2 & 1.0 & 0.0000001 \\
\hline Symptoms & 3.6 & 1.4 & 2.8 & 1.1 & 0.003 & 3.3 & 1.3 & 5.9 & 1.1 & 0.0000001 \\
\hline
\end{tabular}

$\mathrm{p}$-value $<0.05$ (significant in bold). 
Table 10 Parents' gender and QLCCDQ scores

\begin{tabular}{lccccc}
\hline Domain & \multicolumn{2}{c}{ Male } & \multicolumn{2}{c}{ Female } & p-value \\
& Mean & SD & Mean & SD & \\
\hline Family roles & 5.61 & 1.23 & 4.79 & 1.42 & $\mathbf{0 . 0 3}$ \\
Social roles & 5.45 & 1.35 & 4.47 & 1.71 & $\mathbf{0 . 0 4}$ \\
Occupational & 5.38 & 1.28 & 4.74 & 1.68 & $>0.5$ \\
Roles limitations & 5.45 & 1.17 & 4.65 & 1.45 & $>0.5$ \\
Emotions & 5.78 & 1.05 & 4.76 & 1.35 & $\mathbf{0 . 0 0 3}$ \\
Symptoms & 3.74 & 1.24 & 2.85 & 1.30 & $\mathbf{0 . 0 9}$ \\
\hline
\end{tabular}

$\mathrm{p}$-value $<0.05$ (significant in bold)

the tool with parents of children with asthma or diabetes was successful and would be helpful in teamoriented approaches in patient care, where parents would become integral part of the team involved in therapy.

QLCCDQ has a potential to contribute to many aspects of routine care including improved detection of emotional consequences of child's disease and assessment of treatment outcomes in the context of family functioning. The HRQOL feedback can provide important information for both child and family tailored approach in treatment. Studying the feasibility of this questionnaire to measure HRQOL of parents of children with other chronic conditions as the result of child's disease would be of great interest and subject to further research.

\section{Conclusions}

The QLCCDQ shows good internal consistency, test-retest reliability, and construct validity. The questionnaire may be useful in helping to understand the impact chronic child's disease on parental perception of health outcomes.

\section{List of abbreviations}

CHQ PF 50: Child Health Outcomes Questionnaire Parent Form; HRQOL: health - related quality of life; PACQLQ: Pediatric Asthma Caregiver's Quality of Life Questionnaire; PAQLQ: Pediatric Asthma Quality of Life Questionnaire; PDQOL: Pediatric Diabetes Quality of Life Questionnaire; QLCCDQ: Quality of Life in a Child's Chronic Disease Questionnaire; SF 36: Medical Outcomes Survey Short Form; WE-CARE: Well being and Satisfaction of CAREgivers for Children with Diabetes Questionnaire.

\section{Acknowledgements}

The respiratory survey was sponsored by scientific grant from State Committee for Scientific Research (Polish Ministry of Scientific Research and Information Technology). The authors are grateful to Dr. Donna C. Rennie, BN, MN, PhD and Josh Lawson, BSC, MSc, PhD [Canadian Centre for Health and Safety in Agriculture (CCHSA); University of Saskatchewan] for their help in editing the manuscript.

\section{Author details}

'Department of Pneumonology, Medical University of Silesia, Katowice, Poland. ${ }^{2}$ Department of Epidemiology, Medical University of Silesia, Katowice, Poland. ${ }^{3}$ Department of Biostatistics, Faculty of Public Health, Medical University of Silesia, Bytom, Poland. ${ }^{4}$ Information Technology Center, Medical University of Silesia, Katowice, Poland.

\section{Authors' contributions}

MF, JZ, WP and GB conceived of the study and participated in study design, data interpretation. $Ł W M F$ conducted qualitative study, cognitive debriefing and developed the questionnaire, MF, GB, MS JZ WP conducted psychometric study, GB, ŁW, MS were responsible for statistical analysis. MF $\mathrm{GB}, \mathrm{kW}$ worked on manuscript. All authors read and approved the final manuscript.

\section{Competing interests}

The authors declare that they have no competing interests.

Received: 21 January 2010 Accepted: 23 December 2010 Published: 23 December 2010

\section{References}

1. Hyland ME, Finnis S, Irvine SH: A scale for assessing quality of life in adult asthma sufferers. J Psychosom Res 1991, 35:99-110.

2. Juniper EF: How Important is of Life in Pediatric Asthma? Ped Pulmon 1997, suppl 15: 17-21.

3. Juniper EF, Wisniewski ME, Cox FM, Emmet AH, Nielsen KE, O'Byrne PM: Relationship between quality of life and measures of clinical status in asthma: a factor analysis. Eur Respir J 2004, 23:287-291.

4. Faulkner MS, Clark FS: Quality of life for parents of children and adolescents with type 1 diabetes. Diabetes Educ 1998, 24(6):721-7.

5. Vandagriff $J \mathrm{~L}$, Marrero DG, Ingelsoll GM, Fineberg NS: Parents of children with diabetes: what are they worried about? Diabetes Educ 1992, 18(4):299-302.

6. Townsend M, Feeny DH, Guyatt G, Furlong WJ, Seip AE, Dolovich J: Evaluation of burden of illness for pediatric asthmatic patients and their parents. Annals Allergy 1991, 67:403-408.

7. Skoner D: Outcome Measures in Childhood Asthma. Ped 2002, 109:393-398.

8. Schor EL: Family pediatrics: report of the Task Force on the Family. Pediatrics 2003, 111(6):1541-71.

9. Petrou S: Methodological Issues Raised by Preference-Based Approach to Measuring the Health Status of Children. Health Economics 2003, 12(8):697-702.

10. Stewart AL, Hays R, Ware JE: The MOS short form general health survey. Reliability and validity in a patient population. Med Care 1988, 26:724-732.

11. The EuroQol Group A new facility for the measurement of health related quality of life. Health Policy 1990, 16:199-208.

12. Feeny D, Furlong W, Barr RD, Torrance GW, Rosenbaum P, Weitzman SA: A comprehensive system for classifying the health status of survivors of childhood cancer. J Clin Oncol 1992, 10:923-928.

13. Kaplan RM, Anderson JP, Wu AW, Matthews WC, Kozin F, Orenstein D: The Quality of Well-being Scale: application in AIDS, cystic fibrosis and arthritis. Med Care 1989, 27:S27-S43.

14. Lewin AB, Storch EA, Silverstein JH, Baumeister AL, Strawser MS, Geffken GR: Validation of the pediatric inventory for parents in mothers of children with type 1 diabetes: an examination of parenting stress, anxiety, and childhood psychopathology. Fam Syst Health 2005, 23:56-65.

15. Streisand R, Swift E, Wickmark T, Chen R, Holmes CS: Pediatric parenting stress among parents of children with type 1 diabetes: the role of selfefficacy, responsibility, and fear. J Pediatr Psychol 2005, 30:513-521.

16. Stem REK, Riessman CK: The development of an impact on-family scale: Preliminary findings. Med Care 1980, 18:465-472.

17. Cappelleri JC, Gerber RA, Quattrin T, Deutschmann R, Luo X, Arbuckle R, Abetz $L$ : Development and validation of the Well-being and Satisdaction of CAREgivers of Children with Diabetes Questionnaire (WE-CARE). Health Qual Life Outcomes 2008, 6:3.

18. Juniper EF, Guyatt GH, Feeny DH, Ferrie J, Griffith LE, Townsend M: Measuring quality of life in parents of children with asthma. Qual Life Res 1996, 5:27-34.

19. Berdeaux G, Hervie C, Smajda C, Marquis P: Parental quality of life and recurrent ETN infections in their children: development of a questionnaire. Rhinitis Survey Group Qual Life Rea 1998, 7(6):501-12.

20. Arnould B: Patient-reported outcomes and clinical practice. From measurement instruments to decision tools: much more than a simple change format. PRO Newsletter 2006, 36(1):21-24. 
21. Pratheepawanit N, Finlay IG: Quality of life assessment in routine clinical practice: lessons learned from a two-year study. PRO Newsletter 2006, 36(1):25-28.

22. Marks GB, Dunn SM, Woolcock AJ: A scale for the measurement of quality of life in adults with asthma. J Clin Epidemiol 1992, 45:461-472.

23. Guyatt $G$, Juniper E, Griffith $L$, Feeny $D$, Ferrie P: Children and Adult Perception of Childhood Asthma. Ped 1997, 99(2):165-168.

24. Bateman ED, Hurd SS, Barnes PJ, Bousquet J, Drazen JM, Fitzgerald M, Gibson P, Ohta K, O'Byrne P, Petersen SE, Pizzichini E, Sullivan SD, Wenzel SE, Zar HJ: Global Strategy for Asthma Management and Prevention, Global Initiative for Asthma Management and Prevention: GINA executive summary. Eur Respir J 2008, 31:143-178 [http://www. ginasthma.org].

25. Monnier L, Colette C, Owens DR: Glycemic Variability: The Third Component of the Dysglycemia in Diabetes. Is It Important? How to Measure It? Diabetes Sci Technol 2008, 2(6):1094-1100.

26. Mugno D, Ruta L, D'Arrigo VG, Mazzone L: Impairment of quality of life in parents of children and adolescents with pervasive developmental disorder. Health Qual Life Outcomes 2007, 27(5):22.

doi:10.1186/1477-7525-8-151

Cite this article as: Farnik et al: Development, evaluation and validation of a new instrument for measurement quality of life in the parents of children with chronic disease. Health and Quality of Life Outcomes 2010 8:151.

\section{Submit your next manuscript to BioMed Central and take full advantage of:}

- Convenient online submission

- Thorough peer review

- No space constraints or color figure charges

- Immediate publication on acceptance

- Inclusion in PubMed, CAS, Scopus and Google Scholar

- Research which is freely available for redistribution

Submit your manuscript at www.biomedcentral.com/submit 